Rev. Interd. em Cult. e Soc. (RICS), São Luís, v. 7, n. 2, p. 1- 13, jul./dez. 2021

ISSN eletrônico: $2447-6498$

\title{
O desamparo da ciência na transição para sociedades sustentáveis ${ }^{1}$
}

\section{The science helplessness in sustainable societies transition}

\author{
ALCI ALBIERO JÚNIOR \\ Pós-doutorado junto ao programa de Pós-graduação em Ciências Florestais e Ambientais da \\ Universidade Federal do Amazonas (UFAM) pelo programa Nacional de Cooperação \\ Acadêmica na Amazônia n 21/2018- CAPES. \\ albiero.aj@gmail.com
}

\section{RESUMO}

Esse trabalho se constrói diante a conjuntura da virada ontológica das ciências humanas e ambientais. Período em que as crises da sociedade contemporânea exigem da ciência o reconhecimento da potência agentiva de humanos e não humanos na transição para sociedades sustentáveis. Assim, reconhecendo a necessidade da corporificação política para a transição, o destaque e desafio do trabalho é buscar novos caminhos para a corporificação política da ciência através do desamparo como afeto político central, aproximando o campo psicanalítico do reconhecimento das dimensões multiespécie da antropologia contemporânea. Para isso me apoio principalmente nos trabalhos de Vladimir Safatle, Sigmund Freud e Anna Tsing.

Palavras-chave: Afetos. Antropoceno. Contingência. Multiespécie. Sustentabilidade.

\begin{abstract}
This work is constructed in the conjuncture of the ontological turn of human and environmental sciences. A period when the crisis of contemporary society requires science to recognize the active potential of humans and non-humans in the face of the transition to sustainable societies. Thus, recognizing the need for political embodiment in the transition, the highlight, and challenge of the work is to seek new paths for the political embodiment of science through helplessness as a central political affection, bringing the psychoanalytic field closer to the recognition of the multispecies dimensions of contemporary anthropology. For that, I supported the works by Vladimir Safatle, Sigmund Freud, and Anna Tsing.
\end{abstract}

Keywords: Affect. Anthropocene. Contingency. Multispecies. Sustainability.

\footnotetext{
${ }^{1}$ Artigo submetido para avaliação em 14 de setembro de 2021 e aprovado em 12 de outubro em 2021.
} 
Rev. Interd. em Cult. e Soc. (RICS), São Luís, v. 7, n. 2, p. 1- 13, jul./dez. 2021

ISSN eletrônico: $2447-6498$

\section{INTRODUÇÃO}

Reconhecer a capacidade de suporte do meio ambiente através de modelos determinísticos e probabilístico é uma utopia científica, tornando as avaliações dos processos causadores da crise ambiental contemporânea através de representações racionais fixas uma luta contra a contingência. A busca por representações cada vez mais rígidas do mundo se intensifica na ciência das plantations $^{2}$ (TSING, 2019, p. 59) pois nesse processo a necessidade de controle dos fenômenos naturais é fundamental para a expansão sem transformação diante do progresso que não permite qualquer alteração na essência do projeto em expansão (escalabilidade) (TSING, 2019, p. 176-178). Ou seja, a luta contra a contingência na ciência das plantations se revela na rigidez com o qual os fenômenos naturais são tradados em busca de controle e escalabilidade. Processo claramente observado no monopólio do mercado agrícola pelas empresas Monsanto (Estados Unidos da América), Syngenta (Suíça), Dupont (Estados Unidos da América), Basf (Alemanha), Bayer (Alemanha) e Dow (Estados Unidos da América), consideradas as gigantes da genética ("Gene Giants") que controlam o mercado mundial de sementes comerciais e agroquímicos, refletindo no domínio de relações humanas e não humanas por dependência dos aportes técnicos e científicos.

Embora a ciência das plantations procure ocupar o mundo defendendo-se da contingência através do controle da escalabilidade, a crise da sociedade contemporânea (e.g. pandemia, mudanças climáticas, conversão massiva de florestas em monoculturas agrícolas, perda da biodiversidade, acidificação dos oceanos, precarização do trabalho, desterritorialização capitalista, desigualdade social, avanço da indústria cultural, busca por satisfação ilimitada, perda da narrativa do corpo, vida nua) é integral e multifacetada, fragilizando essa resistência e desvelando nossa dependência das intra-ações ${ }^{3}$ com o mundo e com os seres que o habitam.

Se acreditamos na ciência como percurso capaz de abrir novos caminhos diante da crise multifacetada é premente que esse corpo político utilize a contingência a seu favor, distanciando-se de seu conceito Aristotélico de algo que poderia ser ou não, exigente de

\footnotetext{
${ }^{2}$ Tsing (2019, pg.206 e 226) considera as plantations como máquinas de replicação e simplificação ecológica onde os seres vivos são transformados em recursos (ativos) para a produção do mesmo.

${ }^{3}$ Intra-ações representam ações simultaneamente reciprocas diante encontros e entrelaçamentos humanos e não humanos na construção e desconstrução de mundos (CARDOSO, 2016).
} 
Rev. Interd. em Cult. e Soc. (RICS), São Luís, v. 7, n. 2, p. 1- 13, jul./dez. 2021

ISSN eletrônico: $2447-6498$

expectativas positivas quando o afeto em circulação é a esperança ou negativas quando se conecta ao medo - não existe medo sem esperança e esperança sem medo nos diria Spinoza.

A contingencia exerce papel chave na sociedade contemporânea ou sociedade de risco pois os riscos decorrentes do desenvolvimento científico e industrial a partir do século XX, embora eminentes e irreversíveis, se estabelecem em dimensões de incerteza abertas a processos sociais de definição (BECK, 2010, p. 27), tornando sua legitimação dependentes de disputas políticas e de poder, motivadas muitas vezes por objetivos utilitaristas e imediatistas que ultrapassam o campo da incerteza do método científico e se instauram no campo da incerteza política e moral.

Assim, utilizar a contingência a seu favor é reconhecer a vulnerabilidade da ciência em determinar limites ambientais ou Tipping points, definidos por Lenton et al (2008) como limites críticos no qual uma pequena perturbação pode alterar drasticamente o estado e desenvolvimento de um sistema. Assumindo os riscos e seus limites como integrais e por isso, incapazes de representar rigorosamente o todo através da soma de suas partes. Ou seja, o todo ultrapassa a consciência de partes específicas pois a crise se manifesta através da experiência de um corpo integrado e dinâmico em constante relação, adaptação e aprimoramento com o meio ativo. Nesse sentido, será fundamental que a ciência diante a crise que enfrentamos assuma a contingência através de um devir que, ao não permitir qualquer previsão futura, instaura uma necessidade. Essa necessidade instaurada não está presa a qualquer expectativa e, por isso, é independente de afetos ${ }^{4}$ de medo e esperança, recusando futurismos positivos ou negativos.

Medo e esperança são considerados os principais afetos em circulação na sociedade contemporânea (SAFATLE, 2016), responsáveis pelos vínculos sociais que determinam nosso reconhecimento e nossa identidade. Medo provocado por uma biopolítica que segundo Foucault é imanente ao sujeito através do autocontrole (PELBART, 2007) dirigida pela insegurança da morte social (SAFATLE, 2016, p. 141). E esperança, através da representação do futuro que queremos no presente que vivemos. Por exemplo através da consciência planetária do "bem viver" que oferece utopias para repensarmos as estruturas políticas, o consumo, a produção e distribuição de bens e serviços através de referências a comunidades

\footnotetext{
${ }^{4}$ Afetos são considerados ao longo do texto como propriedades externas aos seres que afetam sua potência de ação.
} 
Rev. Interd. em Cult. e Soc. (RICS), São Luís, v. 7, n. 2, p. 1- 13, jul./dez. 2021

ISSN eletrônico: $2447-6498$

que convivem harmoniosamente com a natureza, orientadas por relações de produção autônoma, sustentáveis e autossuficientes, destacando as experiências e práticas existentes de povos Andinos e Amazônicos da América do Sul (ACOSTA, 2019).

São diversos os caminhos para o apocalipse e para a salvação diante as crises da sociedade contemporânea. Porém, herdar um mundo quebrado sem negá-lo e ainda assim conseguir habitá-lo será nosso grande desafio (HARAWAY, 2016 apud COSTA, 2020) na transição para sociedades sustentáveis. Sociedades sustentáveis não são aqui consideradas como modelos transcendentes para a esperança ambiental, climática, política, econômica, ética e cultural. Sociedades sustentáveis são aqui reconhecidas como aquelas que favorecem intra-ações humanas e não humanas e potencializam o desvelamento de mundos. Sociedades onde os humanos não são os únicos agentes ativos nas coordenações de habitabilidades. Coordenações que representam a emergência não intencional de devires e modos de existência através de encontros que não disfarçam as diferenças, mas a assumem como afetos na (re)construção de mundos. Para a antropóloga e feminista Anne Tsing (2019, p. 148) "A coordenação nos permite reconhecer as ontologias incomensuráveis de vários seres ao mesmo tempo que se observa os devires que eles proporcionam em seus encontros”. É nesse sentido que para Tsing o Antropoceno não seria o período em que as ações humanas se tornaram forças geológicas capazes de alterar o clima da terra, mas o momento em que as coordenações são paralisadas. Assim, sociedades sustentáveis serão aquelas que permitem o (re)surgimento das coordenações para a habitabilidade mutiespécie.

Coordenações dependem de intra-ações e são esses encontros promotores de subjetividade $^{5}$ que estão sendo paralisados no Antropoceno. Condição mais complexa de serem (re)criadas se comparadas as estratégias conservacionistas de mitigação climática pela redução das emissões de gazes do efeito estufa impulsionada pela expansão da utilização de energias renováveis ou mercados de carbono. Coordenações surgem a partir de relações incomensuráveis não controladas exclusivamente por agenciamentos humanos, sendo favorecidas pelo desamparo diante a contingência, por isso evitadas na ciência das plantations que exigem o controle dos processos naturais para sua expansão e escalabilidade.

\footnotetext{
5 Subjetividade considerada través da produção, processo e acontecimento como movimento criador entre humanos e não humanos.
} 
Rev. Interd. em Cult. e Soc. (RICS), São Luís, v. 7, n. 2, p. 1- 13, jul./dez. 2021

ISSN eletrônico: $2447-6498$

Diante desse cenário, o presente ensaio busca destacar a potência do desamparo como afeto político central que nos abre a intra-ações e coordenações na transição para sociedades sustentáveis. Nesse processo será importante repensarmos a centralidade do medo e da esperança como afetos principais da corporificação política. Embora tais afetos exerçam grande poder na organização social e construção de identidades coletivas, orientadas de fora para dentro na sociedade disciplinar de Hobbes como de dentro para fora na sociedade do controle de Foucault (PELBART, 2007). Conduzem os indivíduos a deslocarem o ideal do Eu por ideais normativos da massa, orientados pela esperança de demandas de cuidado que fortalecem os papéis sociais estabelecidos e cerceiam a subjetividade necessária para as intraações e coordenações. Para que tais aprisionamentos sejam diluídos o campo político será fundamental, já que os campos da cultura e da economia estão marcados pela desigualdade (SAFATLE, 2016 a, p. 245) e pelo pensamento abissal (DE SOUZA SANTOS, 2007).

A política capaz de desamparar a ciência poderá ser a política de Freud, aquela que não se estabelece nas estruturas atuais de existência (SAFATLE, 2016a, p.94) e por isso capaz de potencializar a transição para um devir sem tempo, ausente de expectativas que tanto nos aprisionam. Destaco que reconhecer a emancipação política em Freud não é algo inelutável, e nesse sentido, Safatle (2016a) resgata Freud e sua concepção do desamparo como afeto político central que nos abre para os vínculos sociais. Nos oferecendo outra perspectiva de organização social através do desamparo como potência política, incorporando esse afeto como condição elementar para a emancipação social destituída de figuras de autoridade. Para Freud (SAFATLE, 2016a. p. 54) "[...] admitir a vulnerabilidade do desamparo é condição fundamental para a emancipação social, isso ocorre porque não se trata aqui de uma experiência de resignação diante da vulnerabilidade, de demanda de cuidado por figuras protopaternas de autoridade ou uma experiência de exploração política contínua do medo". O desamparo aqui abordado seria a condição necessária para o surgimento de certa coragem afirmativa (SAFATLE, 2016a, p. 55), favorecendo a abertura da ciência na transição para sociedades sustentáveis.

Ainda assim, um corpo político será necessário, já que não existe política sem corpo e só um corpo é capaz de enfrentar outro corpo (SAFATLE, 2016a, p. 95). Nesse sentido, como seria esse corpo político da ciência que não se orienta através do medo e da esperança e nem 
Rev. Interd. em Cult. e Soc. (RICS), São Luís, v. 7, n. 2, p. 1- 13, jul./dez. 2021

ISSN eletrônico: $2447-6498$

tampouco pela cultura e pela economia? Que corpo seria esse capaz de nos guiar na transição para sociedades sustentáveis?

Nesse processo de corporificação política, considerar a liberdade como autonomia garantida pela autorrealização individual e coletiva será algo a ser superado. Pois ortogonalmente ao esperado faz do ideal empresarial de si o dispositivo controlador dos indivíduos na sociedade contemporânea (SAFATLE, 2016a, p. 139). Condicionando os sujeitos a estarem em constante aperfeiçoamento de si mesmo, levando-os inevitavelmente a sentimentos de culpa e angústia por nunca se satisfazerem através de suas realizações, tornando os sujeitos os únicos responsáveis pelos seus fracassos em decorrência de sua incapacidade de se reinventar (SAFATLE, 2016b). O credor nunca esteve tão próximo do devedor como na sociedade contemporânea, isso porque ele se tornou o próprio indivíduo. Além disso, ao instituir a autorrealização individual e coletiva como demanda política, se fortalece uma hierarquia intrínseca de propriedade e proprietário, nos revelando que a liberdade como autonomia dos sujeitos no neoliberalismo na verdade se revela como servidão disciplinar e autocontrole (SAFATLE, 2016b).

Tais críticas, reforçam a necessidade de repensarmos a liberdade como forma de superar a opressão social através da autorrealização. $O$ desamparo diante a contingência não garantirá a liberdade individual ou coletiva através da autonomia de dar a mim mesmo minhas próprias regras. Já reconhecemos que essa perspectiva favorece a dialética Hegeliana do senhor e do escravo, necessitando de figuras autoritárias de poder para a organização social, fortalecendo o medo, angústia, esperança e o narcisismo que tanto reforçam as contradições.

O desamparo com os qual nos depararemos nos abrirá para a liberdade como heteronomia sem servidão (DERRIDA, 2003 apud SAFATLE, 2019). Heteronomia sem servidão significa utilizar a contingência a nosso favor e a partir do qual criamos, significa a diluição da necessidade da expectativa, o desabamento da ideia de que ser livre é se guiar pela própria lei, desamparo capaz de me abrir a um domínio que não é meu e nem do outro, pois o outro também é desamparado. Significa que o que me despossui de meus predicados e me abre a contingência não está no outro e nem em mim, mas sim na potencialidade de ação. Perante essa corporificação política será necessário reconhecermos a liberdade mesmo quando não controlamos completamente aquilo que acreditamos nos pertencer. Segundo Safatle (2019, p.34): 
Rev. Interd. em Cult. e Soc. (RICS), São Luís, v. 7, n. 2, p. 1- 13, jul./dez. 2021

ISSN eletrônico: $2447-6498$

Esta outra concepção não dirá que liberdade é autonomia. Ela dirá que liberdade é saber que há sempre uma alteridade profunda que me afeta e me transforma, que por isto minhas ações nunca são completamente minhas. Pensar assim nos deixaria mais aptos a ouvir aquilo que nos atravessa sem nunca adquirir a forma de nós mesmos.

Diante dessa perspectiva, observaremos o desamparo do desenvolvimento científico puramente por aplicações técnicas dirigidas por interesses econômicos e financiados por grupos poderosos que detém a informação e direcionam as revoluções científicas no sentido paradigmático de Khun (2017). Responsáveis por excessos de informações que muitas vezes nada oferecem a vida das pessoas e no desaparecimento da criatividade científica a favor do retorno financeiro (CORREDOIRA, 2013). Condição extremamente crítica considerando que o imperativo da violência simbólica apregoado ao excesso de informação é velado para grande parte da população. Tornando o sujeito cognoscente incapaz de reconhecer o real interesse de dominação que sustenta a informação, sendo incapaz de avaliar e criticar a realidade e se abrir diante a contingência, já que a base de nossa emancipação é intrínseca a compreensão dos nossos mecanismos de sujeição (SAFATLE, 2020, p. 24).

Portanto, aproximar as coordenações de Tsing, o desamparo de Freud e a heteronomia sem servidão de Derrida nos conduz a corpos políticos não cerceados diante a transição para sociedade sustentáveis. Tornando o desamparo como potência política emancipatória fundamental para experienciarmos a liberdade como heteronomia sem servidão e enfrentar o desabamento das estruturas atuais existentes como a política de Freud nos sugere e como a transição para sociedades sustentáveis exige. Além de apoio da política de Freud, que considera a consciência um estágio fugidio (FREUD, 2018, p. 209), também poderemos nos conduzir através da visão ecológica multiespécie da política, abordagem antiessencialista que considera o não humano como agente político (OGDEN et al. 2013). Reforço o cuidado para não simplificarmos política as ações humanas sobre o ambiente, destacando que o desamparo como afeto político central na transição para sociedades sustentáveis é fonte de ação e devires humanos e não humanos. Portanto, se somos humanos através de outros seres, não seria um espanto considerar a política através da ação humana e não humana (BRAUM E WHATMORE, 2010 apud OGDEN et al. 2013).

Mas onde esses corpos políticos se encontram? A cartografia política nos conduzirá as fronteiras. Locais onde os ativos escaláveis da ciência das plantations perdem sua força de ação, permitindo a emergência de corpos políticos desamparados e seus devires não 
Rev. Interd. em Cult. e Soc. (RICS), São Luís, v. 7, n. 2, p. 1- 13, jul./dez. 2021

ISSN eletrônico: $2447-6498$

escaláveis. Processo complexo e dinâmico, onde os humanos não são os únicos agentes da mudança, mas fazem parte de coordenações multiespécies capazes de grande potência (re)criadora de intra-ações promotoras de habitabilidade. Tsing (2019, p.7) considera as fronteiras como as ruinas do Antropoceno: "As paisagens globais de hoje estão repletas desse tipo de ruína. Ainda assim, esses lugares podem ser animados apesar dos anúncios de sua morte; campos de ativos abandonados às vezes geram novas vidas multiespécie e multiculturais".

Em áreas fragmentadas e sob efeitos de borda da floresta Amazônica brasileira, consideradas fronteiras entre florestas e plantations, árvores que ocupam o dossel da floresta reduziram seu crescimento durante os primeiros 10 anos de fragmentação, oposto as árvores que ocupavam o sub-bosque da floresta que se favoreceram pelo maior aporte de luz diante a criação da borda e aumentaram seu crescimento diamétrico ao longo dos primeiros 20 anos de fragmentação (ALBIERO JUNIOR et al, 2019; 2021). Diante o desamparo a que foram submetidas nesse novo ambiente fragmentado e de ruinas, as árvores recriam suas intra-ações e coordenações, alterando suas dinâmicas de vida ao longo do tempo. Por serem seres longevos as árvores podem nos oferecer muitas histórias sobre seu desamparo e liberdade nas ruinas do Antropoceno, como as reveladas através de seus anéis de crescimento nos trabalhos de Abiero Junior et al $(2019 ; 2021)$.

As árvores são importantes agentes de entrelaçamento político humano e não humano. Na maior floresta tropical do mundo, árvores amazônicas favorecem intra-ações fundamentais para a entrada total de água doce nos oceanos e a fixação fotossintética da biomassa de carbono terrestre (FAUSET et al., 2015). Indispensáveis para o balanço energético e a manutenção do clima do planeta (HILKER et al., 2014; WANG E FU, 2007). O crescimento das árvores varia ao longo de sua vida e se torna contingente à medida que suas coordenações (e.g. sol, chuva, animais, outras árvores, solo, humanos) são desenvolvidas. Assim, não considerar as variações de crescimento entre árvores diferentes favoreceram a superexploração madeireira e subutilização do potencial madeireiro na floresta Amazônica. Levando Schöngart et al. $(2003 ; 2008)$ a proporem restrições no ciclo de corte e diâmetro mínimo de corte em áreas de manejo florestal, estabelecendo modelos específicos a partir das informações reveladas pelas próprias árvores Amazônicas através de seus anéis de crescimento. Diante o entrelaçamento árvores e humanos, “[...] a ciência e a técnica não são 
Rev. Interd. em Cult. e Soc. (RICS), São Luís, v. 7, n. 2, p. 1- 13, jul./dez. 2021

ISSN eletrônico: $2447-6498$

notáveis por serem verdadeiras ou eficazes, mas sim porque multiplicam os não-humanos envolvidos na construção de coletivos e porque tornam mais intima a comunidade que formamos com esses seres" (LATOUR, 1994, p. 135).

Tais entrelaçamentos, além de demonstrarem a capacidade agentivas das árvores nos revelam que as coordenações são formas de comunicação entre humanos e não humanos. Como os anéis de crescimento, que desvelam intra-ações e representações ativas do mundo ao longo da vida das árvores. Representações que para Eduardo Kohn, em seu livro: How forest think: towar na anthropology beyond the human (2013, p. 221), podem devolver e ampliar nosso olhar para o mundo através de um olhar em conjunto com outras criaturas.

Segundo Anne Tsing apud Cardoso (2019), nossos encontros nos contaminam e à medida que somos contaminados novas direções e mundos surgirão. Diante das ruinas do Antropoceno, corpos políticos desamparados poderão encontrar a coragem afirmativa necessária para o devir sem tempo diante da crise. É através dessa contaminação promotora de coragem afirmativa que encontraremos corpos políticos capazes de se abrir através da transição para sociedades sustentáveis. Na transição para sociedades sustentáveis, o quebrarse diante ao desamparo nos conduzirá a novas representações que fazemos da união sociedade e ciência. Feyerabend (2011, p. 21) em seu "anárquico" contra o método coloca a participação social como obrigatória nas discussões e desenvolvimento científico já que essa é parte integrada ao sistema. Porém, na corporificação política da ciência através do desamparo, ciência e sociedade estarão ausentes de identidades que as hierarquizem, se orientando apenas pela necessidade de ação através de intra-ações que não pretendem validar um conhecimento pelo outro.

Nas ruinas periféricas do Antropoceno as alterações ambientais são reconhecidas por desconfigurarem coordenações desenvolvidas e por isso exigem ação e devires na (re)criação de habitabilidades. Nesses locais, o critério de demarcação do conhecimento científico não estará cerceado a estruturas de representação racionais fixas distantes de sua realidade, seu critério de desenvolvimento serão as próprias intra-ações promotoras de coordenações. Como as árvores da floresta Amazônica que alteraram suas dinâmicas de crescimento quando desamparadas pela fragmentação e efeitos de borda, embora permanecendo nesse ambiente "arruinado" através da (re)criação de intra-ações registradas em seus anéis de crescimento. 
Rev. Interd. em Cult. e Soc. (RICS), São Luís, v. 7, n. 2, p. 1- 13, jul./dez. 2021

ISSN eletrônico: $2447-6498$

Portanto, para o desamparo da ciência e sua não dominação pelo poder de especialistas, posições hierárquicas e gêneros específicos, será importante que o corpo político na transição para sociedades sustentáveis possa ser aquele despossuído de um líder que se reconhece como líder. Oque pode significar a necessidade de um corpo político desidêntico, embora capaz de reconhecimento diante a transição para sociedades sustentáveis. Corpo político humano e não humano como as árvores da floresta Amazônica que através de suas dinâmicas de crescimento agenciam o clima da terra. ${ }^{6}$

A força do poder político sempre esteve associada a ilusão de que entre o poder e seus sujeitos há uma profunda relação de identidade e reconhecimento, prática que será arruinada por Lacan (SAFATLE, 2020, p. 25), já que a cura em Lacan está ligada a certa dissolução do Eu (SAFATLE, 2015, p. 249). Embora já presente de certa maneira na obra "Moisés e o Monoteísmo", onde Freud através da etimologia, da psicanálise (mito do herói) e da história (existência de um faraó que tentava implementar a religião monoteísta no Egito), confirma que Moises, o herói do povo Judeu, seu libertador, legislador, educador e fundador da religião era de origem Egípcia (FREUD, 2018, p. 27), ou seja, um líder desidentico.

$\mathrm{O}$ reconhecimento através da identidade fortalece a rigidez do $\mathrm{Eu}$, refletindo em suas relações sempre marcadas pela agressividade, pelo conflito e redução narcísica do outro (SAFATLE, 2020, p. 22). Safatle (2020) destaca que Lacan ao compreender que somos causados por algo que nuca nos será idêntico e por isso nunca será objeto de um domínico, nos oferece a noção antipredicativa de reconhecimento. Teoria dos corpos políticos desidenticos que ultrapassa a noção de reconhecimento através da identidade ou do lugar vazio do poder, que ainda assim possibilitaria a representação do líder através do retorno do reprimido (FREUD, 2018, p. 181). Portanto, se buscamos o desamparo da ciência na transição para sociedades sustentáveis, a noção antipredicativa de reconhecimento de forte influência lacaniana poderá direcionar os corpos políticos a heteronomia sem servidão e aos devires sem tempo promotores das intra-ações criadoras de coordenações. Nesse processo, desamparar-se através de perspectivas mais que humanas será fundamental para a dissolução da alteridade antropogênica em direção as coordenações promotoras de habitabilidade, e trabalhos como os

\footnotetext{
6 “A floresta amazônica não somente mantém o ar úmido para si mesma, mas exporta rios aéreos de vapor que, transportam a água para as chuvas fartas que irrigam regiões distantes no verão hemisférico" (NOBRE, 2014).
} 
Rev. Interd. em Cult. e Soc. (RICS), São Luís, v. 7, n. 2, p. 1- 13, jul./dez. 2021

ISSN eletrônico: $2447-6498$

de Carvalho et al (2020) destacando a potência pedagógica das plantas como sujeitos mais que humanos serão importantes fontes para o reconhecimento antipredicativo.

A ciência diante a transição para sociedades sustentáveis poderá encontrar no desamparo a coragem afirmativa necessária para a corporificação política e organização social ausente de predicados e por isso capaz de reconhecer novas formas de resolução de problemas orientadas por corpos políticos que se reconhecem através de identidades fortemente indeterminadas, abertas a contingencia e por isso capazes de lidar com um corpo que não é completamente estruturado, levando a uma maior solidariedade com aquilo que no outro não sou capaz de incorporar (SAFATLE, 2016a, p. 242). Através dessa abertura, o reconhecimento dos indivíduos e suas relações com o trabalho e o meio ambiente não estarão apenas vinculados e subjugados a doutrinas de controle interno e externo, mas se orientarão pela temporalidade de um devir sem tempo.

É evidente que o desamparo como afeto político central que nos abre a ação diante a contingência na transição para sociedades sustentáveis exigirá que corpos sejam quebrados para superarmos a forma como nos relacionamos com nós mesmos, com a sociedade e com o meio ambiente. Porém, a ciência do desamparo nos exigirá essa coragem afirmativa.

Como diria o poeta Ferreira Gullar "O sentido da vida é o outro". E que esse outro diante a transição para sociedade sustentável seja humano e não humano.

\section{AGRADECIMENTOS}

Agradeço principalmente a Érica Speglich pela orientação durante o desenvolvimento do trabalho e a Thiago Mota Cardoso e Rosana Louro Ferreira Silva pelas colaborações e sugestões.

\section{REFERÊNCIAS}

ACOSTA, A. O bem viver: uma oportunidade para imaginar outros mundos. Editora Elefante, 2019.

ALBIERO JÚNIOR, A.; VENEGAS_GONZÁLEZ, A.; BOTOSSO, P. C.; CAMARGO, J. L. C.; ROIG, F. A.; TOMAZELLO_FILHO, M. Forest fragmentation and edge effects temporarily favored understory and midstory tree growth. Trees. No prelo. 2021. 
Rev. Interd. em Cult. e Soc. (RICS), São Luís, v. 7, n. 2, p. 1- 13, jul./dez. 2021 ISSN eletrônico: 2447-6498

ALBIERO JÚNIOR, A.; VENEGAS_GONZÁLEZ, A.; BOTOSSO, P. C.; CAMARGO, J. L. C.; ROIG, F. A.; TOMAZELLO_FILHO, M. What is the temporal extension of edge effects on tree growth dynamics? A dendrochronological approach model using Scleronema micranthum (Ducke) Ducke trees of a fragmented forest in the Central Amazon. Ecol Indic v.101:133-142. 2019.

BECK, U. Sociedade de risco: rumo a uma outra modernidade. Editora 34, 2010.

CAMPOS, M. A. de A. Na roça com os Pataxó: etnografia multiespécie da mandioca na aldeia Barra Velha do Monte Pascoal, Sul da Bahia. Piracicaba, Tese (Doutorado em Ecologia Aplicada) - ESALQ/USP, 2016.

CARDOSO, T. M. Paisagens em transe: uma etnografia sobre poética e cosmopolítica dos lugares habitados pelos Pataxó no Monte Pascoal. Florianópolis, Tese (Doutorado em Antropologia Social) - UFSC, 2016.

CARDOSO, T. M. A arte de viver no antropoceno: um olhar etnográfico sobre cogumelos e capitalismo na obra de Anna Tsing. Climacom cultura científica - pesquisa, jornalismo e arte, v. 6, p. 1, 2019.

CARVALHO, I. C. de M.; STEIL, C. A.; GONZAGA, A. F. Learning from a more-thanhuman perspective. Plants as teachers, The Journal of Environmental Education, v. 51, n. 2, p. 144-155, 2020.

CORREDOIRA, M. L. The Twilight of the Scientific Age. Universal-Publishers, 2013. Disponível em: 〈https://arxiv.org/pdf/1305.4144.pdf>.

COSTA, A. Por uma verdade capaz de imprever o fim do mundo. Coletiva: Revista de divulgação científica, v. 27, p. 1-10, 2020.

FAUSET, S.; JOHNSON, M.O.; GLOOR, M.; BAKER, T.R.; MONTEAGUDO, A.; BRIENEN, R. J. W.; FELDPAUSCH, T. R.; LOPEZ_GONZALEZ, G.; MALHI, Y., TER STEEGE, H. Hyperdominance in Amazonian forest carbon cycling. Nat. Commun, v. 6, p. 7857-7866, 2015.

FEYERABEND, P, K. Contra o método. São Paulo, UNESP, 2011.

FREUD, S. Totem e tabu. Trad. Paulo César de Souza. Obras Completas, v. 11, 2013.

FREUD, S. Moisés e o monoteísmo, compêndio de psicanálise e outros textos. Trad. Paulo César de Souza. Obras Completas, v. 19, 2018.

HILKER, T.; LYAPUSTIN, A. I.; TUCKER, C. J.; HALL, F. G.; MYNENI, R. B.; WANG, Y., B, J.; DE MOURA, Y. M.; SELLERS, P. J. Vegetation dynamics and rainfall sensitivity of the Amazon. Proc. Natl. Acad. Sci, v. 111, p. 16041-16046, 2014.

KOHN, E. How forests think: toward an anthropology beyond the human. Berkeley: University of California Press, 2013. 
Rev. Interd. em Cult. e Soc. (RICS), São Luís, v. 7, n. 2, p. 1- 13, jul./dez. 2021 ISSN eletrônico: $2447-6498$

KHUN, T. S. A estrutura das revoluções científicas. São Paulo, Perspectiva, 2017.

LATOUR, B. Jamais fomos modernos. Editora 34, 1994.

LENTON, T. M.; HELD, H.; KRIEGLER, E.; HALL, J. W.; LUCHT, W.; RAHMSTORF, S.; SCHELLNHUBER, H. J. Tipping elements in the Earth's climate system. Proceedings of the national Academy of Sciences, v. 105, n. 6, p. 1786-1793, 2008.

NOBRE, A. D. O futuro climático da Amazônia. Relatório de Avaliação Científica. São José dos Campos, São Paulo, 2014.

OGDEN, L. A.; BILLY, H.; KIMIKO, T.; Animals, plants, people, and things: A review of multispecies ethnography. Environment and Society, v. 4. n.1, p. 5-24, 2013.

PÁL PELBART, P. Biopolítica. Sala Preta, v. 7, p. 57-66, 2007.

SAFATLE, V. Introdução a Jacques Lacan. Autêntica, 2015.

SAFATLE, V. O circuito dos afetos: corpos políticos, desamparo e o fim do indivíduo. Autêntica, 2016a.

SAFATLE, V. "Quando as ruas queimam: manifesto pela emergência" Série Pandemia. São Paulo, n-1 editora, 2016b.

SAFATLE, V. Crítica da autonomia: liberdade como heteronomia sem servidão. Discurso, v. 49.2, p.21-41, 2019.

SAFATLE, V. Maneiras de transformar mundos: Lacan, política e emancipação. Autêntica Editora, 2020.

SCHÖNGART, J. Biomass increment, dynamics and modelling of the growth of white water floodplain. Göttingen, These (Doutor em Ciências Florestais) - University of Göttingen, 2003.

SCHÖNGART, J. Growth-Oriented Logging (GOL): A new concept towards sustainable forest management in Central Amazonian várzea floodplains. Forest Ecology and Management, v. 256, p. 46-58, 2008.

TSING, A. L. Viver nas ruínas: paisagens multiespécies no Antropoceno. Brasília, IEB Mil folhas, 2019.

WANG, H.; FU. R. The influence of Amazon rainfall on the Atlantic ITCZ through convectively coupled Kelvin waves. J. Clim, v. 20, p. 1188-1201, 2007. 